\title{
Ground uplift related to permeability enhancement following the 2011 Tohoku earthquake in the Kanto Plain, Japan
}

\author{
Kazuya Ishitsuka ${ }^{1 *}$, Toshifumi Matsuoka ${ }^{2,3}$, Takuya Nishimura ${ }^{4}$, Takeshi Tsuji ${ }^{5,6}$ and Tamer ElGharbawi ${ }^{7}$
}

\begin{abstract}
We investigated the post-seismic surface displacement of the 2011 Tohoku earthquake around the Kanto Plain (including the capital area of Japan), which is located approximately $400 \mathrm{~km}$ from the epicenter, using a global positioning system network during 2005-2015 and persistent scatterer interferometry of TerraSAR-X data from March 2011 to November 2012. Uniform uplift owing to viscoelastic relaxation and afterslip on the plain has been reported previously. In addition to the general trend, we identified areas where the surface displacement velocity was faster than the surrounding areas, as much as $\sim 7 \mathrm{~mm} /$ year for 3 years after the earthquake and with a velocity decay over time. Local uplift areas were $\sim 30 \times 50 \mathrm{~km}^{2}$ and showed a complex spatial distribution with an irregular shape. Based on an observed groundwater level increase, we deduce that the local ground uplift was induced by a permeability enhancement and a pore pressure increase in the aquifer system, which is attributable to mainshock vibration.
\end{abstract}

Keywords: Post-seismic displacement, 2011 Tohoku earthquake, Synthetic aperture radar interferometry, Permeability enhancement, Tokyo

\section{Introduction}

The Mw 9.0 Tohoku earthquake occurred off the coast of Japan on March 11, 2011 (Fig. 1a). It caused strain changes in the Japanese islands, specifically an east-west extension of the islands from the eastward displacement and subsidence along the Pacific coast (Ozawa et al. 2011). In addition to the overall island displacement, studies of local displacement have reported new displacement phenomena. One example is the strain anomalies of the Tohoku earthquake that result from crustal inhomogeneities, as reported by Takahashi (2011), Ohzono et al. (2012), and Nishimura et al. (2016). Another is volcanic subsidence, as indicated by Ozawa and Fujita (2013) and Takada and Fukushima (2013).

Post-seismic displacement continued after the 2011 Tohoku earthquake (Nishimura 2014). Horizontal movement toward a mainshock fault was observed. Vertical uplift occurred in the fore-arc region, which is relatively

\footnotetext{
*Correspondence: ishitsuka@eng.hokudai.ac.jp

${ }^{1}$ Division of Sustainable Resources Engineering, Hokkaido University, Kita

13, Nishi 8, Kita-ku, Sapporo, Hokkaido 060-8628, Japan

Full list of author information is available at the end of the article
}

close to the epicenter, whereas subsidence resulted in the back-arc region. The observed land displacement was modeled by viscoelastic rebound and afterslip on the mainshock fault (Ozawa et al. 2012; Sun et al. 2014; Diao et al. 2014; Silverii et al. 2014; Yamagiwa et al. 2015). Although these crustal displacements on the scale of an island arc have been discussed, local surface displacement has rarely been investigated. ElGharbawi and Tamura (2015a) estimated the post-seismic displacement of the Boso Peninsula (the southeast part of the Kanto Plain), using InSAR time series analysis and global positioning system (GPS) data; however, detailed and overall patterns of similar displacements after the 2011 earthquake around the Kanto region have not been studied.

In this study, we investigated the detailed surface displacement of the Kanto Plain (including the capital area of Japan) (Fig. 1) after the 2011 Tohoku earthquake. We used a GPS and persistent scatterer interferometry (PSI) analysis of TerraSAR-X data. These modern geodetic methods enable the mapping of surface displacement with high accuracy and spatial density. We used a nationwide GPS network, termed GEONET (GNSS Earth 

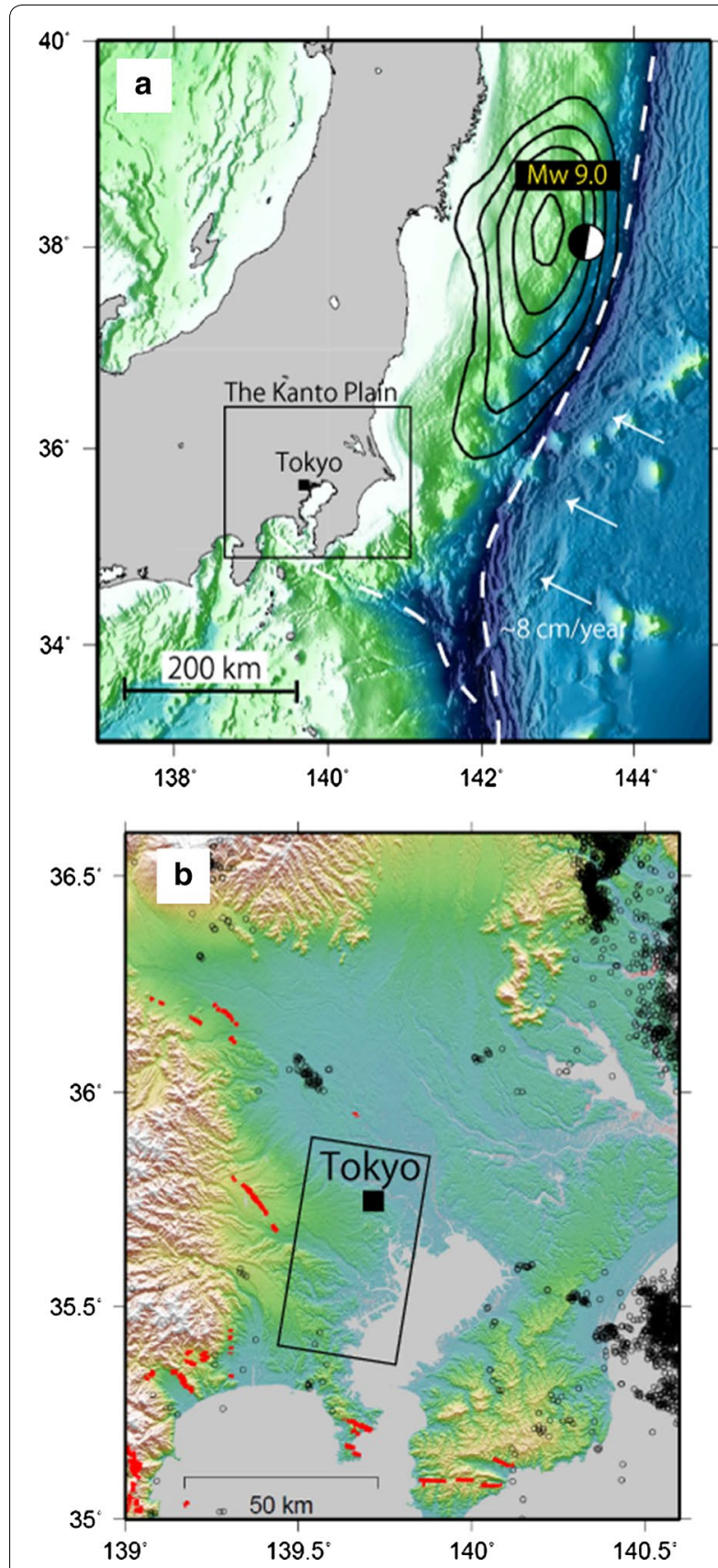

Fig. 1 a The epicenter and the slip area for the mainshock of the 2011 Tohoku earthquake overlaid on seafloor topography. Contour lines are the 5-m interval slip distribution of the mainshock (Ozawa et al. 2011), and a black square represents the Kanto Plain. A black rectangle indicates the studied area, which corresponds to Figs. 2 and 3. b Topography of the Kanto Plain. A black square is the location of Tokyo. Red lines are active fault traces plotted according to Nakata and Imaizumi (2002), and black dots are the locations of aftershocks that occurred from March 11, 2011, to December 31, 2011. A black rectangle in $(\mathbf{b})$ is the covered area of TerraSAR-X image
Observation Network System), with a spacing of $\sim 20$ $30 \mathrm{~km}$. PSI analysis can map surface displacements with a higher spatial density. TerraSAR-X images have a spatial resolution of $\sim 1 \mathrm{~m} \times 2 \mathrm{~m}$. The TerraSAR-X system uses $\mathrm{X}$-band radar with a wavelength of $\sim 3.2 \mathrm{~cm}$, which is the shortest among modern SAR satellites, and therefore, it has increased sensitivity to surface displacement because of this short wavelength.

Groundwater level changes around a ruptured fault has been presumed to be induced by strain changes caused by an earthquake, and surface displacements related to groundwater level changes were observed in the 1992 Landers (Johnston et al. 1995) and 2000 Iceland (Jonsson et al. 2003) earthquakes. Groundwater level changes have been observed even in areas that are located more than one fault length from the mainshock fault. Because of the great distance from the ruptured fault, these changes are not attributed to strain changes but rather to permeability changes in the aquifer system, which are induced by the removal of colloids and bubbles that block pores by earthquake vibration (Montgomery and Manga 2003; Manga et al. 2003, 2012). For permeability changes, intrinsic differences in pore pressure can cause fluid flow (Manga et al. 2012). Such a permeability change has been observed, for instance, in the 1952 Kern Country earthquake (Manga et al. 2003), the 1989 Loma Prieta earthquake (Rojstaczer and Wolf 1992), and the 1995 Kobe earthquake (Sato and Takahashi 1996; Tokunaga 1999; Sato et al. 2000). For the Kanto Plain, a permeability change caused by the 2011 earthquake was estimated by Nakata and Snieder (2012), using seismic velocity variations. The increase in permeability after major earthquakes has been reported in oil fields, which occurred through a removal of asphaltene particles that were deposited in narrow pore throats within the oil reservoir (Uetani et al. 2016). Ground displacement is expected from pore fluid flow resulting from a permeability change after powerful earthquakes. However, geodetic observations of the poroelastic displacement that is associated with permeability and groundwater flow changes have seldom been reported. We argue that local heterogeneous ground uplift on the Kanto Plain after the 2011 Tohoku earthquake can be explained by permeability enhancement.

\section{Data and methodology}

We determined the surface displacement of the Kanto Plain using GEONET data, whose associated GPS network is operated by the Geospatial Information Authority of Japan (GSI) (Hatanaka et al. 2003). Daily GEONET 
coordinates are termed F3 solutions and are publically available. We used the daily coordinates from 120 stations around the Kanto Plain, which were recorded through the end of 2015. Before processing the GPS coordinates, possible steps from antennae replacements or maintenance work were removed manually, according to the offset data provided by the GSI. The annual displacement of SAR acquisition dates (Fig. 5) was derived by averaging the daily coordinates over 10 days before and after the date of interest. Final estimates of surface displacements were obtained as absolute values in the International Terrestrial Reference Frame 2005, without using a reference site.

To densify the displacement pattern that was derived from the GPS network, we performed PSI analysis using 32 TerraSAR-X data south of Tokyo, which was acquired from March 2011 to November 2012 (see Additional file 1: Table S1). This analysis selects coherent pixels, which are termed persistent scatterers, and estimates pixel displacement. Physically, persistent scatterers typically correspond to manmade structures or bare (i.e., unvegetated) surfaces. Therefore, urban areas, which represent typical surfaces in the area of interest, are suitable target areas for PSI analysis (e.g., Ishitsuka et al. 2014). PSI studies have detected surface displacements with millimeter accuracy using TerraSAR-X data (e.g., Crosetto et al. 2016).

We performed PSI analysis by selecting PS candidate pixels using an amplitude dispersion index threshold of 0.3 (Ferretti et al. 2001). Then, differential interferograms were created with a single pass (i.e., at full resolution). PS pixels were selected from the candidate pixels by choosing pixels with a temporal coherence \pm 0.70 (Ferretti et al. 2001). Phase unwrapping was done using a minimum cost flow algorithm (Costantini and Rosen 1999). Subsequently, tropospheric phase components were estimated as spatially low-frequency and temporally high-frequency components by filtering in the spatial and temporal domains. Boxcar filtering with a length of $\sim 0.7 \mathrm{~km}$ was done in the spatial domain, and one-dimensional filtering with a triangular shape and a length of 400 days was conducted in the temporal domain. The filtration size was determined based on a simulation study that considered temporal sampling of SAR data (Ishitsuka et al. 2015). The estimated tropospheric phase components were subtracted from the unwrapped interferograms. Subsequently, vertical displacement was estimated by subtracting the horizontal displacement that was derived from a cubic convolution interpolation of horizontal changes in 120 GPS stations that surrounded the SAR data (Keys 1981). Finally, a surface displacement velocity was estimated by applying a best-fit linear function, assuming a constant velocity for the surface displacement.

\section{Processed results}

\section{Surface displacement derived from GPS data}

We first mapped the vertical surface displacement in the pre- and co-seismic period (Fig. 2). For the former period, we analyzed GPS data from January 2005 to December 2010, whereas data on March 10, 2011, and March 12, 2011, were used to estimate the co-seismic displacement. Although post-seismic displacements over several hours after the earthquake may occur during the period, the magnitude of the post-seismic effect can be neglected compared with the co-seismic displacement.
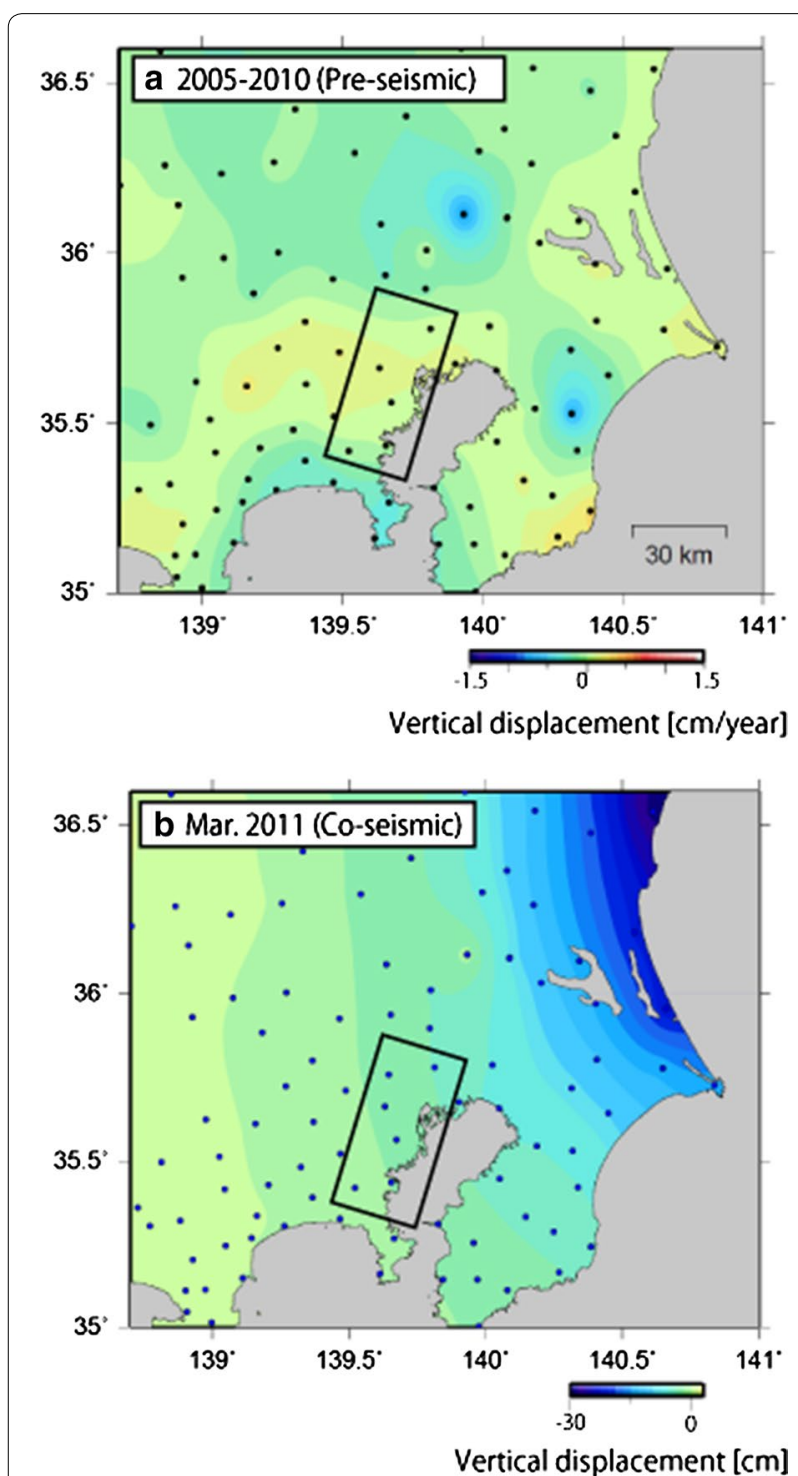

Fig. 2 a Annual vertical surface displacement velocity from January 2005 to December 2010 (the period before the 2011 Tohoku earthquake), derived from the GPS network. b Vertical surface displacement from March 10, 2011, to March 12, 2011 (co-seismic period), derived from the GPS network. Black rectangles are the covered areas of TerraSAR-X images 
In the pre-seismic period, we found two subsidence areas to the north and east of the area, which were reported as the result of groundwater/gas extraction (e.g., Deguchi et al. 2009; Ishitsuka et al. 2016; Fig. 2a). An uplift area of displacement up to $5 \mathrm{~mm}$ /year existed from the center to south of the Kanto Plain, which resulted from the subduction of the Sagami Trough. We mapped the annual displacement velocity from 2005 to 2010 (Fig. 2a). In Fig. 3, the secular displacement velocity from 2005 to 2010 in Fig. 2a was subtracted to map transient displacements. Figure $3 \mathrm{a} 2$ shows an enlarged view of the displacements around the center and south of the area shown in Fig. 3a1, and the displacements are with respect to a reference GPS location, which is located in the northeast of the enlarged area. Transient displacements less than $1.5 \mathrm{~cm} /$ year existed during this period (Fig. 3a1 and a2). A co-seismic displacement showed a strong subsidence pattern, with displacement as large as $30 \mathrm{~cm}$ (Fig. 2b). The subsidence increased toward the northeast part of the area, which is attributed to the mainshock of the 2011 earthquake. Almost all surface displacements can be explained by the mainshock (Ozawa et al. 2011).

The surface displacement velocity of the Kanto Plain for the post-seismic period April 2011 to December 2011 was derived from GEONET (Fig. 3b1 and b2). In the horizontal direction, the ground surface continued to move eastwardly by as much as $30 \mathrm{~cm} /$ year from the source area of the Tohoku earthquake (Fig. 3b1 and b2). The ground has been uplifted vertically by as much as $1-10 \mathrm{~cm} /$ year; this pattern is opposite that of the co-seismic period (Figs. 2b, 3b1, b2). The uplift in the eastern part is mostly greater than that in the west. This uplift pattern is well known and is explained by the numerical modeling of viscoelastic relaxation and afterslip (Ozawa et al. 2012; Sun et al. 2014; Diao et al. 2014; Silverii et al. 2014; Yamagiwa et al. 2015).

In addition to this general uplift pattern, we found that the area southwest of Tokyo had a local significant surface uplift velocity of approximately several centimeters per year, especially during the $\sim 3$ years after the earthquake (Fig. 3b2). This magnitude of transient displacements was not observed six years before the earthquake. Therefore, the higher uplift velocity area was likely induced by the 2011 earthquake. This higher uplift velocity area is roughly elliptical, aligned NW-SE with spatial dimensions of $\sim 30 \times 50 \mathrm{~km}^{2}$, and the area may migrate with time (e.g., dashed lines in Fig. 3b2). As far as we know, sudden anthropogenic changes, such as changes in groundwater use, were not reported during the three years after the earthquake. Therefore, we argue that this local uplift occurred spontaneously. Such a local variation in uplift velocity has not been reported previously and cannot be explained by previous studies of post-seismic displacement.
Examples of temporal changes in vertical surface displacement, with locations in Fig. 3b1, are shown in Fig. 4. The time series data of vertical displacement shows a decaying uplift velocity over time. The higher uplift velocity area was evident between April 2011 and December 2012. However, the uplift velocity of the Kanto Plain became uniform with time. The uplift velocity south of Tokyo was faster initially and then decreased gradually (Fig. 3b1 and b2). In 2011 and 2012, the higher uplift velocity area was non-identical; i.e., the deceleration of this uplift was not uniform in that area.

To understand the relationship between the local uplift and seismicity, we mapped the seismic hypocenters $(M>3.0)$ during 2011 and 2013 as determined by the Japan Meteorological Agency (Fig. 1b). Significant seismic activity shallower than $50 \mathrm{~km}$ occurred off the eastern coast of the Kanto Plain, where the Pacific plate is subducting beneath the plain. No significant seismic activity occurred south of Tokyo, where the uplift velocity was greater than in other areas. This observation suggests that local uplift occurred aseismically.

\section{Surface displacement derived from PSI analysis}

We mapped in detail the area of greater surface uplift velocity from March 2011 to December 2012, using PSI analysis of TerraSAR-X data, according to the processing strategy in "Data and Methodology" section (Fig. 5). A reference point was established northeast of the analysis area, where local uplift was found to be smaller than in other parts of the area. Figure 5 shows that the uplift velocity was faster than at the reference location in several parts of the area. For example, a greater uplift velocity ( $>5 \mathrm{~mm} /$ year) occurred in the west and was less $(<5 \mathrm{~mm} /$ year $)$ in the center and east. The uplift was slower in the north and south $(<1 \mathrm{~mm} /$ year).

Six GPS stations existed within the analysis area of the TerraSAR-X images. Quantitative comparisons between GPS and PSI vertical displacements were made, using five GPS stations relative to one reference station. For comparison, we averaged the vertical GPS displacements acquired during the five days before and after SAR acquisitions. Vertical PSI displacements within $300 \mathrm{~m}$ from GPS locations were averaged. The mean of the absolute difference of time series displacements was $3.0 \mathrm{~mm}$. The accuracy almost corresponded with previous PSI studies using TerraSAR-X, which shows that the PSI result agrees with the GPS data (e.g., Yu et al. 2013; Luo et al. 2014; Barboux et al. 2015). The PSI result demonstrates that the local uplift area did not have a clear ellipsoidal shape, but rather had a more complex spatial pattern, such as a fractal surface, than that inferred by GPS analysis. The length scale of the overall local uplift area is approximately dozens of kilometers and is oriented NW-SE, whereas the 
a1 Displacements around the Kanto plain (2005-2010)
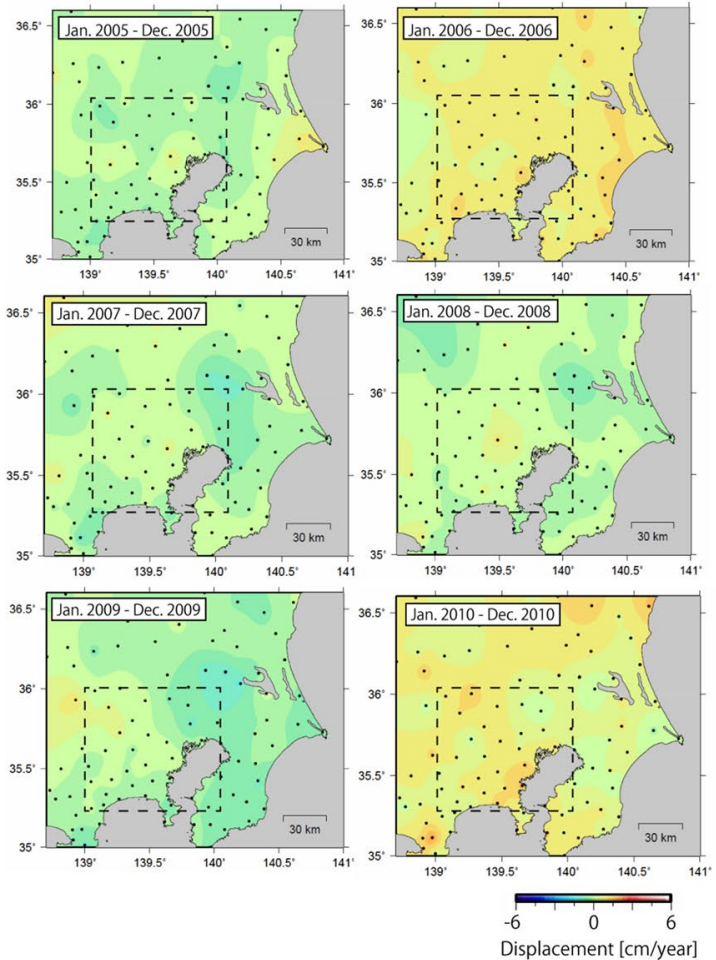

Displacement [cm/year]

a2 Displacements at the center - south of the Kanto plain (2005-2010)
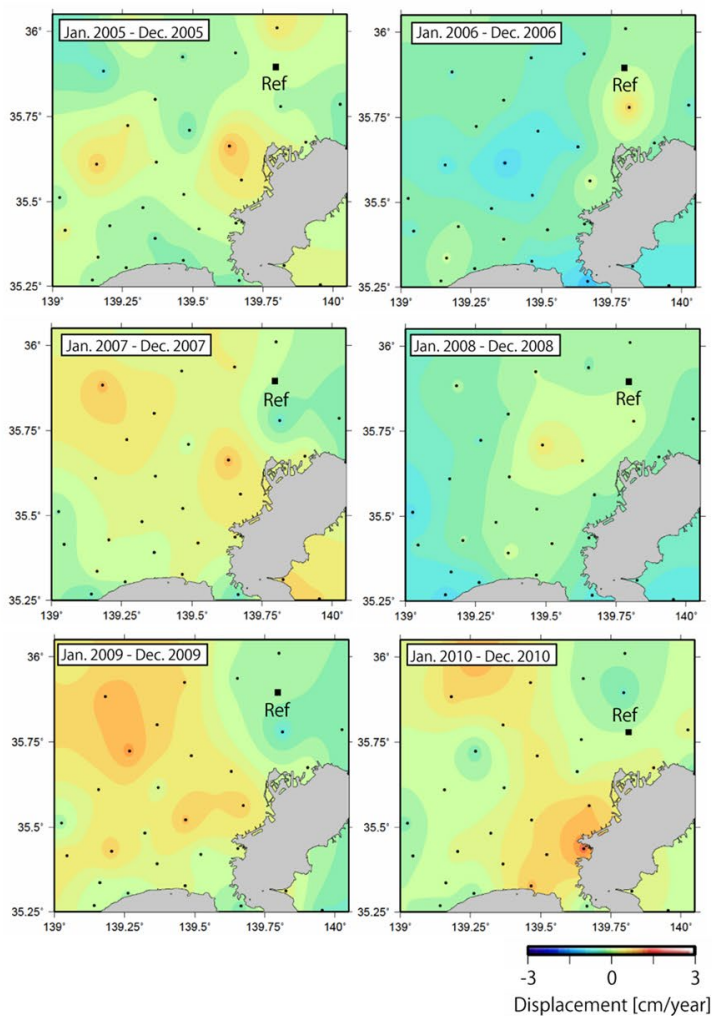
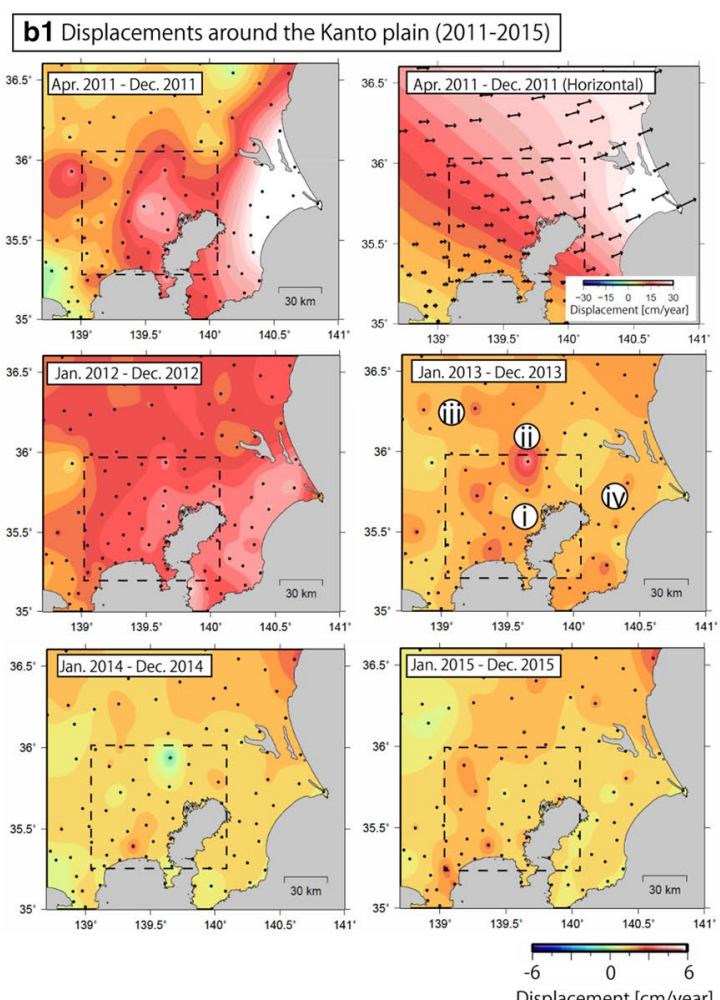

Displacement $[\mathrm{cm} /$ year $]$

b2 Displacements at the center - south of the Kanto plain (2011-2015)
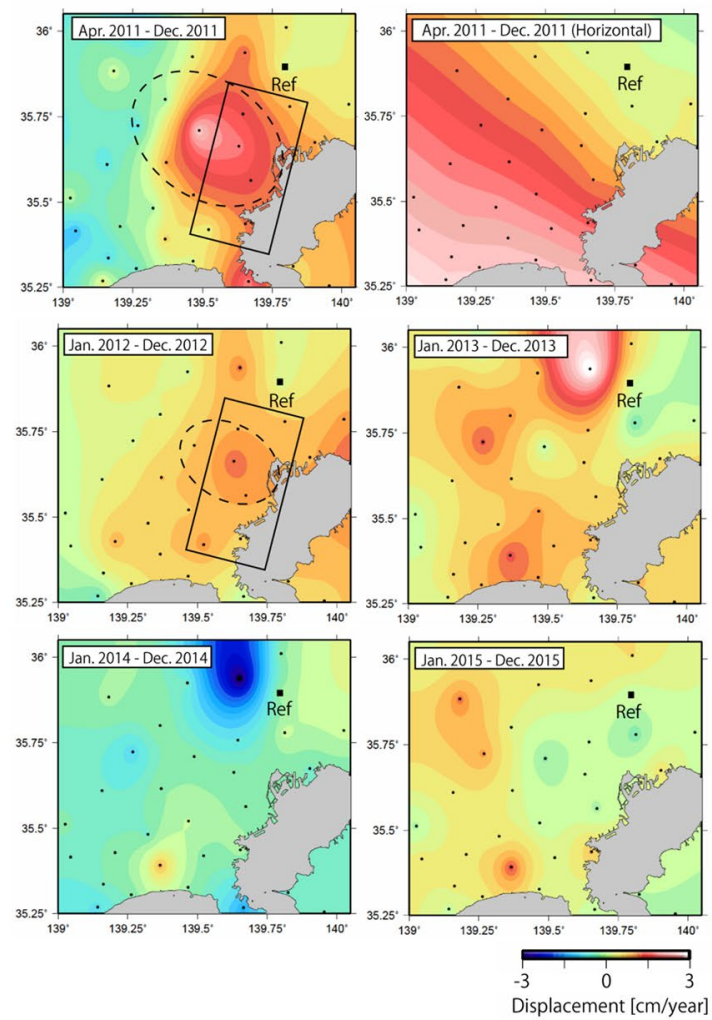
(See figure on previous page.)

Fig. 3 a1 Vertical displacement velocity of the Kanto Plain derived from GEONET during January 2005 to December 2010 (the period before the 2011 Tohoku earthquake). The continuous displacement in Fig. 2a was subtracted from all maps. Black dots are the locations of the GPS stations. a2 Enlarged views around the center-south of the Kanto Plain (corresponding to the dashed rectangles in Fig. 2a1). A reference point is set at the northeast corner of the Kanto Plain, where the surface displacement was relatively stable after the earthquake. In the figure for 2010, a reference point is set south of the reference point for other figures, because subsidence has been observed only in the period. b1 Vertical and horizontal displacement velocity during April 2011 to December 2015. b2 Enlarged views around the center-south of the Kanto Plain (corresponding to the dashed rectangles in Fig. 2b1). The reference point is the same as a2. Black rectangles in 2011 and 2012 are the covered areas of TerraSAR-X images

finer length scale for the edges of the local uplift area is several hundreds of meters to dozens of meters and is oriented in various directions.

\section{Possible mechanisms of local surface uplift}

Four possibilities have been proposed for the mechanism of post-seismic displacement: (1) afterslip of an earthquake fault, (2) viscoelastic relaxation, (3) fault-zone dilatancy recovery (displacement from post-seismic recovery from fault-zone contraction), and (4) poroelastic rebound (displacement owing to groundwater level change) (e.g., Fielding et al. 2009; Wang et al. 2012; Ozawa et al. 2012; Sun et al. 2014; Diao et al. 2014; Silverii et al. 2014; Hu et al. 2014; Yamagiwa et al. 2015). For the 2011 Tohoku earthquake, previous studies have explained island-scale post-seismic deformation using a contribution of these effects. Ozawa et al. (2011) and Silverii et al. (2014) modeled island-scale deformation during several months (seven and four months, respectively) after the earthquake, as afterslip of a fault. Diao et al. (2014) modeled post-seismic deformation of GEONET data up to 560 days after the earthquake by considering afterslip and
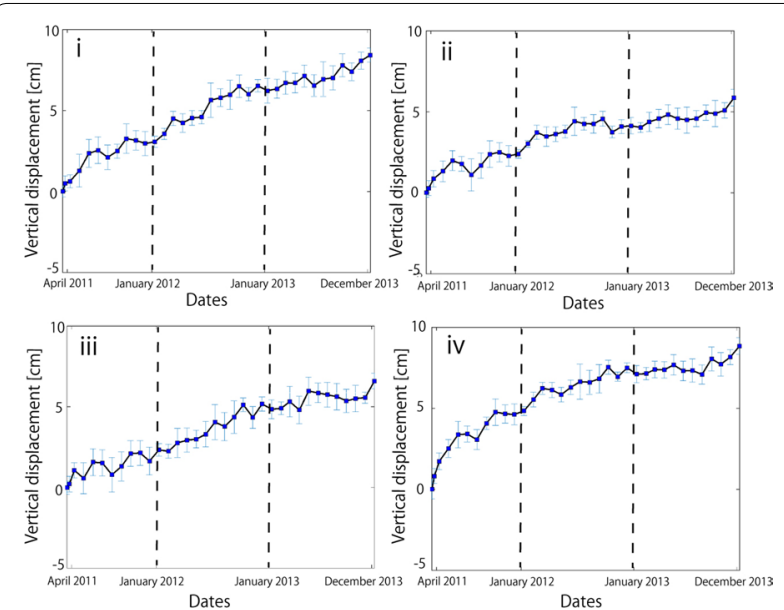

Fig. 4 Time series of vertical surface displacement during April 2011 to December 2013 at selected GPS stations. The locations of (i)-(iv) are in Fig. 3b1. Dashed lines indicate the boundaries of the period used to calculate the annual displacement velocities viscoelastic relaxation. Sun et al. (2014) and Yamagiwa et al. (2015) estimated that viscoelastic relaxation contributed significantly to island-scale deformation for a few years (3.0 and 2.5 years, respectively) based on seafloor GPS and GEONET data. Hu et al. (2014) estimated the amount of poroelastic rebound during the two years after the earthquake from GEONET data and found that the contribution was less significant in onshore areas $(<2 \mathrm{~cm}$ at the coastal area of the Tohoku region, where the distance from the epicenter is $\sim 160 \mathrm{~km}$ ) compared to the contribution of afterslip and viscoelastic relaxation.

For the local uplift that was identified in this study, the probability of afterslip for the local uplift would be low, because the depth of the upper surface of the Pacific plate is $60-80 \mathrm{~km}$ beneath the observed local uplift area (Nakajima et al. 2009), and afterslip at such depths causes a large wavelength surface uplift (i.e., $>50 \mathrm{~km}$ ). No large active faults exist around the local uplift area (Fig. 1b), and a fault slip that was triggered by the 2011 earthquake would not have occurred. The likelihood of viscoelastic relaxation is also low. A heterogeneous viscoelastic structure that causes the irregular-shaped displacement has not been reported. A surface displacement resulting from the heterogeneity of a viscoelastic structure can produce heterogeneous displacement patterns (e.g., Pollitz 2003; Yamasaki and Houseman 2012). However, if such structures exist, they are often assumed to lie $\sim 60 \mathrm{~km}$ beneath the surface (e.g., Pollitz et al. 2008), and spatial characteristics of surface displacement appeared across a wide area (i.e., $>50 \mathrm{~km}$ ). A brittle-ductile transition zone (i.e., $\sim 15-$ $60 \mathrm{~km}$ ) or the lateral fluctuation of Moho [e.g., $<20 \mathrm{~km}$ in the El Mayor Cucapah earthquake (Rollins et al. 2015)] can also cause viscoelastic heterogeneities, and spatial characteristics of surface displacement would appear over a wider area (e.g., $>15 \mathrm{~km})$. It is unlikely that a faultzone dilatancy recovery would be observed in the Kanto Plain. The fault-zone contraction (i.e., fault-zone dilatancy) is induced by pervasive damage from fault slip, which can occur along a main shock fault. Accordingly, our observed spatial heterogeneity of surface displacement cannot be explained by such a mechanism.

In contrast, a poroelastic displacement, which is caused by pore fluid flow, is a plausible mechanism for the observed local uplift in the Kanto Plain. The poroelastic 


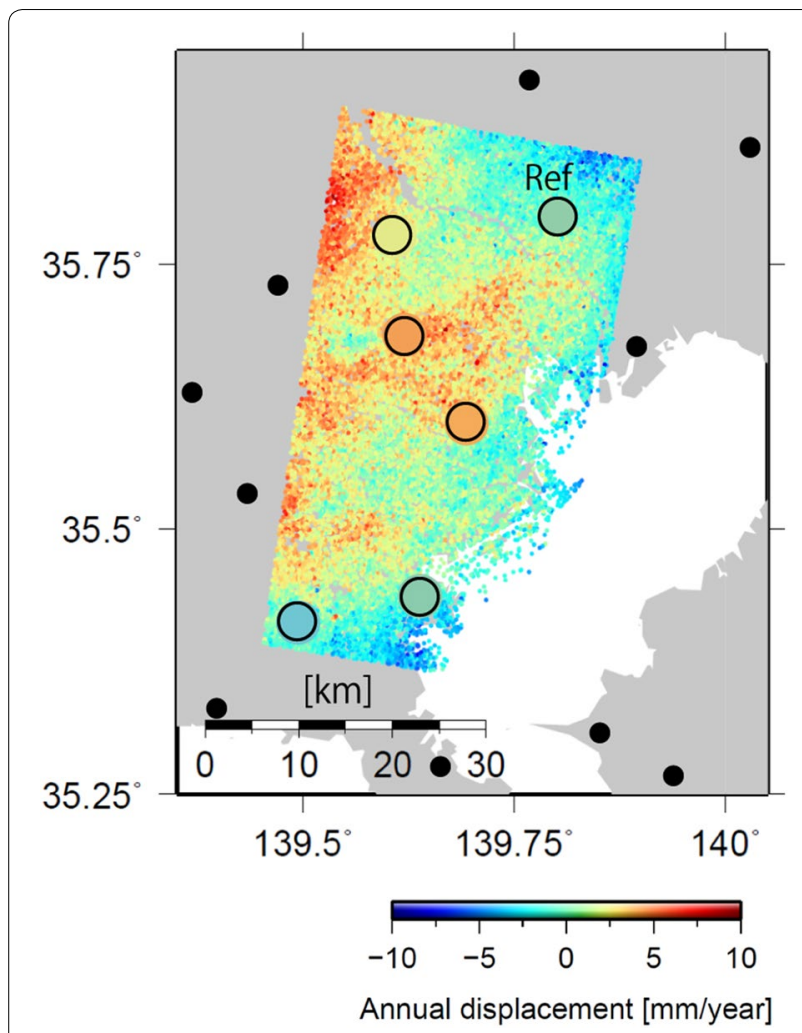

Fig. 5 a Surface displacement velocity derived from PSI analysis of TerraSAR-X images acquired from April 2011 to November 2012. The reference point (assuming deformation velocity is zero) is set at the northeast GPS location of the analyzed area (Ref. in the figure). Colored circles are surface displacement velocities of GPS data within the SAR images, and black dots are GPS locations surrounding the SAR images

displacement by an earthquake was observed previously around the mainshock fault (within a fault length of the ruptured fault) [e.g., the 1992 Landers earthquake by Johnston et al. (1995) and Fialko (2004); the 2000 South Iceland earthquake by Jonsson et al. (2003)]. This model indicates that the cause is the migration of groundwater due to static stress (pore pressure) changes that are induced by an earthquake, which subsequently displaces the ground surface. However, in the Kanto Plain, groundwater flow from changes in the shear stresses is unlikely, because the Kanto Plain is situated far from the ruptured fault. Instead, permeability enhancement is the most likely mechanism of groundwater migration by an earthquake far from a mainshock fault. Indeed, groundwater level changes caused by a permeability increase from earthquakes have been observed previously (Manga et al. 2003, 2012). It is believed that this permeability enhancement by a factor of a few [e.g., $<2$ in southern California by the 1992 Landers earthquake (Elkhoury et al. 2006), $>5$ in Awaji island by the 1995 Kobe earthquake (Tokunaga 1999)] occurs because of mobilizing colloids, including clay minerals and bubbles of non-wetting fluids that trap pores and fractures (Manga et al. 2012). Moreover, long-period (low-frequency) seismic waves can increase permeability (Manga et al. 2012).

Ishihara et al. (2012) reported an increase in groundwater level at Tokyo, $\sim 400 \mathrm{~km}$ from the epicenter, 1 month after the 2011 earthquake. To understand the groundwater level change in greater detail, we mapped the level around Tokyo before and after that earthquake. We used data from 36 groundwater wells at depths of 5-50 m from the ground surface, from the Bureau of Construction of the Tokyo Metropolitan Government, and data from 7 groundwater wells from the Kanagawa prefectural government. Monthly groundwater levels were obtained from the continuous operation of the observation wells. Figure 6 shows the annual groundwater level changes in (a) January 2009-December 2010 (pre-seismic period), (b) April 2011-December 2011 (first post-seismic period), (c) January 2012-December 2012 (second postseismic period), and (d) January 2013-December 2013 (third post-seismic period). The annual change was obtained by estimating a constant groundwater level velocity by L1-norm fitting of the monthly groundwater level.

The groundwater level change was $<1 \mathrm{~m} /$ year before the 2011 earthquake (Fig. 6a). The level increased immediately after the earthquake (Fig. 6b). The highest annual velocity was $\sim 4-5 \mathrm{~m}$ /year, which had been rarely observed before the earthquake. This area of greater increase in groundwater level coincided approximately with areas of greater surface uplift velocity (see Fig. 5). In 2012 and 2013, the velocity decreased, and the groundwater level largely stabilized (Fig. 6c, d). Based on the spatial correlation between the groundwater level change and the ground uplift, we speculate that the latter was induced by the former.

Permeability changes in the Kanto Plain after the 2011 earthquake were estimated by Nakata and Snieder (2012) based on changes in the anisotropy coefficients of shear wave velocities of $>40 \%$. Their observations suggest changes in fluid conditions such as a permeability of near-surface cracks in the upper few hundred meters beneath the surface (Nakata and Snieder 2011, 2012). Because the sediment layer beneath the local uplift area is thicker than in other areas ( $>2000-3000 \mathrm{~m}$ thick), which also appear as a negative Bouguer anomaly (e.g., Tada 1982), Furumura et al. (2011) and Furumura (2014) have reported that the velocity response spectrum shows that the earthquake caused long seismic shear waves ( 1-30 s). The geological characteristics would alter the permeability of the aquifer structure and induce pore fluid migration in the area significantly. The local uplift area corresponds approximately to areas of past ground 

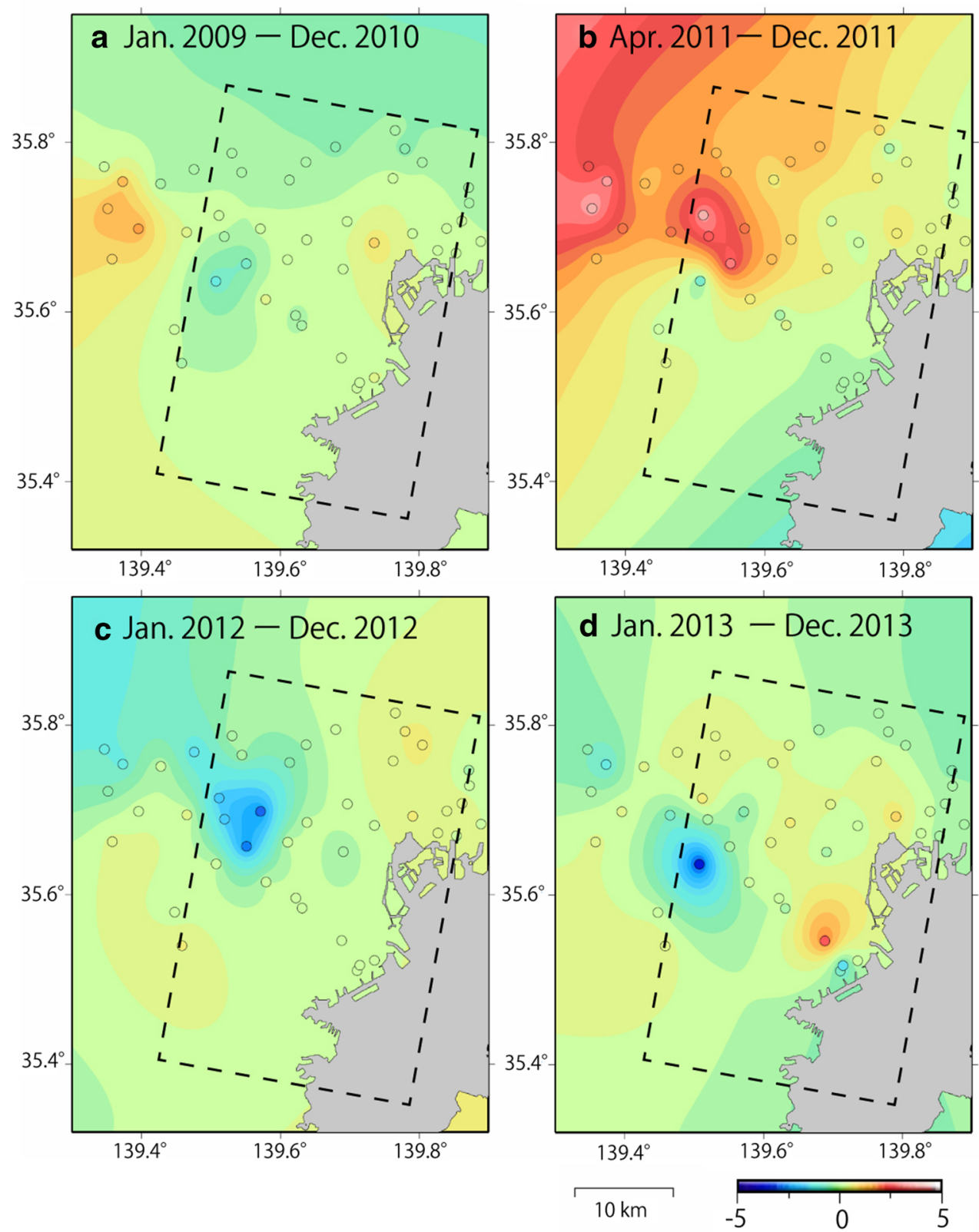

Groundwater level change [m/year]

Fig. 6 The velocity of groundwater level change around Tokyo. a January 2009-December 2010, b April 2011-December 2011, c January 2012December 2012, and d January 2013-December 2013. Positive values indicate increases in groundwater level. Circles and dots are groundwater well locations and GPS locations, respectively. Black dashed lines are TerraSAR-X data coverage used in Fig. 5

uplift of $\sim 2 \mathrm{~cm} /$ year because of groundwater recovery after a reduction in groundwater pumping (Kishi and Nagai 1975). The past observation suggests that a special permeability structure exists that is most likely related to the river basin, and groundwater may tend to migrate beneath the local uplift area. Therefore, we believe that our observation shows a local uplift area that is induced by local permeability enhancement.
In addition to the uplift around Tokyo, which is the focus of this study, smaller local surface displacements were discovered east and north of Kanto Plain (Fig. 3b1). Using an InSAR time series analysis of ENVISAT/ASAR data, ElGharbawi and Tamura (2015a) estimated local uplift at $\sim 20-40 \mathrm{~mm}$ from May 2011 to June 2011 on the southeastern plain. These local surface displacements were associated with likely groundwater 
level changes at several locations on the plain. It has been reported that soil liquefaction occurred extensively in artificial filled areas along the Tokyo bay, which are $\sim 20-50 \mathrm{~km}$ away from the local uplift area in this study (Bhattacharya et al. 2011; Ishitsuka et al. 2012; ElGharbawi and Tamura 2015b). Soil liquefaction is the compaction of soil grains from continuous vibration. Because the occurrence of soil liquefaction causes soil permeability changes and is correlated with lowfrequency seismic waves (>1 s) (e.g., Wang et al. 2003), these observations support a permeability enhancement beneath the local uplift area.

\section{Conclusions}

We identified local surface uplift around Tokyo that occurred during the three years after the 2011 Tohoku earthquake, using a GPS network and PSI analysis of TerraSAR-X data. The area of local uplift was $\sim 30 \times 50 \mathrm{~km}^{2}$ and had an irregular shape, such as a fractal surface. This uplift cannot be explained by the post-seismic deformation models of the earthquake in the previous studies. A comparison of groundwater level changes indicates that the uplift may be attributed to poroelastic rebound. We speculate that local groundwater level changes were induced by permeability changes that were caused by amplified ground shaking, which was influenced by a thick sediment layer in the area. Our results demonstrate a new post-seismic displacement mechanism of the 2011 Tohoku earthquake that is caused by permeability enhancement in areas far from the mainshock fault.

\section{Additional file}

Additional file 1. Table S1. SAR acquisition dates and perpendicular baselines. Bperp indicates perpendicular component of baseline.

\footnotetext{
Author details

1 Division of Sustainable Resources Engineering, Hokkaido University, Kita 13, Nishi 8, Kita-ku, Sapporo, Hokkaido 060-8628, Japan. ${ }^{2}$ Fukada Geological Institute, 2-13-12 Honkomagome, Bunkyo-ku, Tokyo 113-0021, Japan.

${ }^{3}$ Center for the Promotion of Interdisciplinary Education and Research, Kyoto University, Yoshida-honmachi, Sakyo-ku, Kyoto 606-8501, Japan. ${ }^{4}$ Disaster Prevention Research Institute, Kyoto University, Gokasho, Uji, Kyoto 611-0011, Japan. ${ }^{5}$ Department of Earth Resources Engineering, Kyushu University, 744 Motooka, Nishi-ku, Fukuoka 819-0395, Japan. ${ }^{6}$ International Institute for Carbon-Neutral Energy Research (WPI-I2CNER), Kyushu University, 744 Motooka, Nishi-ku, Fukuoka 819-0395, Japan. ${ }^{7}$ Department of Civil Engineering, Misr Higher Institute for Engineering and Technology, Ring Rd, Mansoura, Dakahlia 35511, Egypt.
}

\section{Authors' contributions}

$\mathrm{KI}$ organized this study and drafted the manuscript. KI analyzed and interpreted the SAR data. TN and TE contributed to an analysis and interpretation of GNSS data. TM and TT assisted in the preparation of the manuscript. All authors reviewed the manuscript critically. All authors read and approved the final manuscript.

\section{Acknowledgements}

TerraSAR-X data were provided through the TerraSAR-X scientific service system (Proposal No. GEO2696). The F3 solution of GEONET data as managed by the Geospatial Information Authority of Japan was used to map GPS displacements. Groundwater level data from the Bureau of Construction of the Tokyo Metropolitan Government and the Kanagawa prefectural government were also used. The authors acknowledge the support of KAKENHI Grant Nos. 15H06843, 17K14724 and JST-JICA SATREPS. K. Ishitsuka would like to thank P. Prats-Iraola and M. Nannini for fruitful discussions on PSI processing. There is no potential conflict of interest for any authors that are not apparent from their affiliations or funding. The authors also express appreciation to an editor (Taku Ozawa) and reviewers (Gareth Funning and anonymous one) for their insightful comments.

\section{Competing interests}

The authors declare that they have no competing interests.

\section{Publisher's Note}

Springer Nature remains neutral with regard to jurisdictional claims in published maps and institutional affiliations.

Received: 10 November 2016 Accepted: 5 June 2017

Published online: 19 June 2017

\section{References}

Barboux C, Strozzi T, Delaloye R, Wegmuller U, Collet C (2015) Mapping slope movements in Alpine environments using TerraSAR-X interferometric methods. ISPRS J Photogramm Remote Sens 109:178-192. doi:10.1016/j. isprsjprs.2015.09.010

Bhattacharya S, Hydo M, Goda K, Tazoh T, Taylor CA (2011) Liquefaction of soil in the Tokyo Bay area from the 2011 Tohoku (Japan) earthquake. Soil Dyn Earthq Eng 31:1618-1628. doi:10.1016/j.soildyn.2011.06.0006

Costantini M, Rosen PA (1999) A generalized phase unwrapping approach for sparse data. In: Proceedings of IGARSS'99, pp 267-269. Hamburg. doi:10.1109/IGARSS.1999.773467

Crosetto M, Monserrat O, Cuevas-González M, Devanthéry N, Crippa B (2016) Persistent scatterer interferometry: a review. ISPRS J Photogramm Remote Sens 115:78-89. doi:10.1016/j.isprsjprs.2015.10.011

Deguchi T, Rokugawa S, Matsushima J (2009) Long-term ground displacement measurement by time series analysis for SAR interferometry. J Remote Sens Soc Jpn 29(2):418-428. doi:10.11440/rssj.29.418

Diao F, Xiong X, Wang R, Zheng Y, Walter TR, Weng H, Li J (2014) Overlapping post-seismic displacement processes: afterslip and viscoelastic relaxation following the 2011 Mw 9.0 Tohoku (Japan) earthquake. Geophys J Int 196(1):218-229. doi:10.1093/gji/ggt376

ElGharbawi T, Tamura M (2015a) Coseismic and postseismic displacement estimation of the 2011 Tohoku earthquake in the Kanto region, Japan, using InSAR time series analysis and GPS. Remote Sens Environ 168:374-387. doi:10.1016/j.rse.2015.07.016

ElGharbawi T, Tamura M (2015b) Estimating deformation due to soil liquefaction in Urayasu city, Japan using permanent scatterers. ISPRS J Photogramm Remote Sens 109:152-164. doi:10.1016/j. isprsjprs.2015.09.002

Elkhoury JE, Brodsky EE, Agnew DC (2006) Seismic waves increase permeability. Nature 441:1135-1138. doi:10.1038/nature04798

Ferretti A, Prati C, Rocca F (2001) Permanent Scatterers in SAR Interferometry. IEEE Geosci Remote Sens 39:8-20. doi:10.1109/36.898661

Fialko Y (2004) Evidence of fluid-filled upper crust from observations of postseismic deformation due to the 1992 Mw7.3 Landers earthquake. J Geophys Res 109:B08401. doi:10.1029/2004JB002985

Fielding EJ, Lundgren PR, Bürgmann R, Funning GJ (2009) Shallow faultzone dilatancy recovery after the 2003 Bam earthquake in Iran. Nature 458:64-68. doi:10.1038/nature07817

Furumura T (2014) Risk of long-period ground motion due to the deep basement structure of the Kanto Plain. J Geogr 123(4):434-450. doi:10.5026/ jgeography.123.434 
Furumura T, Takemura S, Noguchi S, Takemoto T, Maeda T, Iwai K, Padhy S (2011) Strong ground motions from the 2011 off-the Pacific-Coast-ofTohoku, Japan ( $M w=9.0)$ earthquake obtained from a dense nationwide seismic network. Landslides 8:333-338. doi:10.1007/s10346-011-0279-3

Hatanaka Y, lizuka T, Sawada M, Yamagiwa A, Kikuta Y, Johnson JM, Rocken C (2003) Improvement of the analysis strategy of GEONET. Bull GSI 49:11-37

Hu Y, Bürgmann R, Freymuller JT, Banerjee P, Wang K (2014) Contributions of poroelastic rebound and a weak volcanic arc to the postseismic deformation of the 2011 Tohoku earthquake. Earth Planets Space 66:106. doi:10.1186/1880-5981-66-106

Ishihara S, Kawamura A, Amaguchi H, Takasaki T, Kawai M (2012) Characteristics of unconfined and confined groundwater level fluctuation in Tokyo by the 2011 off the pacific coast of Tohoku earthquake. JSCE J 68(4):I_595I_600. doi:10.2208/jsce/jscejhe.68.I_595

Ishitsuka K, Tsuji T, Matsuoka T (2012) Detection and mapping of soil liquefaction in the 2011 Tohoku earthquake using SAR interferometry. Earth Planets Space 64:1267-1276. doi:10.5047/eps.2012.11.002

Ishitsuka K, Fukushima Y, Tsuji T, Yamada Y, Matsuoka T, Giao PH (2014) Natural surface rebound of the Bangkok plain and aquifer characterization by persistent scatterer interferometry. Geochem Geophys Geosyst 15(4):965-974. doi:10.1002/2013GC005154

Ishitsuka K, Prats-Iraola P, Nannini M (2015) ALOS/PALSAR and TerraSAR-X persistent scatterer interferometry around Tokyo: interferometric phase evaluation and validation. Proc IGARSS 2015:1421-1424. doi:10.1109/ IGRASS.2015.7326044

Ishitsuka K, Matsuoka T, Takahashi T, Aizawa T (2016) Ground subsidence in the northern Kanto Plain by persistent scatterer SAR interferometry. Zairyo 65(5):384-390. doi:10.2472/jsms.65.384

Johnston MJS, Hill DP, Linde AT, Langbein J, Bilham R (1995) Transient displacement during triggered seismicity from the June $1992 \mathrm{Mw}=7.3$ Landers earthquake at Long valley volcanic caldera, California. Bull Seismol Soc Am 85(3):787-795

Jonsson S, Segall P, Pedersen R, Bjornsson G (2003) Post-earthquake ground movements correlated to pore-pressure transients. Nature 424:179-183. doi:10.1038/nature01776

Keys RG (1981) Cubic convolution interpolation for digital image processing. IEEE Trans Acoust Speech Signal Process ASSP 29(6):1153-1160. doi:10.1109/TASSP.1981.1163711

Kishi K, Nagai S (1975) The study about unusual ground uplift around Kawasaki region. Chishitsu News 254

Luo Q, Perissin D, Lin H, Zhang Y, Wang W (2014) Subsidence monitoring of Tiajin suburbs by TerraSAR-X persistent scatterer interferometry. J Sel Top Appl Earth Obs Remote Sens 7(5):1642-1650. doi:10.1109/JSTAR.2013.2271501

Manga M, Brodsky EE, Boone M (2003) Response of stream flow to multiple earthquakes. Geophys Res Lett 30(5):1214. doi:10.1029/2002GL016618

Manga M, Beresnev I, Brodsky EE, Elkhoury JE, Elsworth D, Ingebritsen SE, Mays DC, Wang C-Y (2012) Change in permeability caused by transient stresses: field observations, experiments, and mechanisms. Rev Geophys 50:RG2004. doi:10.1029/2011RG000382

Montgomery DR, Manga M (2003) Streamflow and water well responses to earthquakes. Science 300:2047-2049. doi:10.1126/science.1082980

Nakajima J, Hirose F, Hasegawa A (2009) Seismotectonics beneath the Tokyo metropolitan area, Japan: effect of slab-slab contact and overlap on seismicity. J Geophys Res 114:B08309. doi:1 0.1029/2008JB006101

Nakata T, Imaizumi T (2002) Digital active fault map of Japan. University of Tokyo Press, Tokyo

Nakata N, Snieder R (2011) Near-surface weakening in Japan after the 2011 TohokuOki earthquake. Geophys Res Lett 38:L17302. doi:10.1029/2011GL048800

Nakata N, Snieder R (2012) Time-lapse change in anisotropy in Japan's near surface caused by the 2011 Tohoku-oki earthquake. Geophys Res Lett 39:L11313. doi:10.1029/2012GL051979

Nishimura T (2014) Pre-, co-, and post-seismic displacement of the 2011 Tohoku-oki earthquake and its implication to a paradox in short-term and long-term displacement. J Disaster Res. doi:10.20965/jdr.2014.p0294

Nishimura T, Suito H, Kobayashi T, Dong Q, Shibayama T (2016) Excess strain in the Echigo Plain sedimentary basin, NE Japan: evidence from coseismic displacement of the 2011 Tohoku-oki earthquake. Geophys J Int 205(3):1613-1617. doi:10.1093/gji/ggw102

Ohzono M, Yabe Y, linuma T, Ohta Y, Miura S, Tachibana K, Sato T, Demachi T (2012) Strain anomalies induced by the 2011 Tohoku earthquake (Mw
9.0) as observed by a dense GPS network in northeastern Japan. Earth Planets Space 64:1231-1238. doi:10.5047/eps.2012.05.015

Ozawa T, Fujita E (2013) Local deformation around volcanoes associated with the 2011 off the Pacific coast of Tohoku earthquake. J Geophys Res 118:390-405. doi:10.1029/2011JB009129

Ozawa S, Nishimura T, Suito H, Kobayashi T, Tobita M, Imakiire T (2011) Coseismic and postseismic slip of the 2011 magnitude-9 Tohoku-Oki earthquake. Nature 475:373-376. doi:10.1038/nature10227

Ozawa S, Nishimura T, Munekane H, Suito H, Kobayashi T, Tobita M, Imakiire T (2012) Preceding, coseismic, and postseismic slips of the 2011 Tohoku earthquake, Japan. J Geophys Res 117:B07404. doi:10.1029/2011 JB009120

Pollitz FF (2003) Post-seismic relaxation theory on a laterally heterogeneous viscoelastic model. Geophys J Int 155:57-78. doi:10.1046/j.1365-246X.2003.01980.x

Pollitz F, Banerjee P, Grijalva K, Nagarajan B, Bürgmann R (2008) Effect of 3-D viscoelastic structure on post-seismic relaxation from the $2004 \mathrm{M}=9.2$ Sumatra earthquake. Geophys J Int 173:189-204. doi:10.1111/j.1365-246X.2007.03666.x

Rojstaczer S, Wolf S (1992) Permeability changes associated with large earthquakes: an example from Loma Prieta, California. Geology 20:211-214. doi:10.1130/0091-7613

Rollins C, Barbot S, Avouac J-P (2015) Post-seismic deformation following the $2010 \mathrm{M}=7.2 \mathrm{El}$ Mayor-Cucapah earthquake: observations, kinematic inversions, and dynamic models. Pure Appl Geophys 172:1305-1358. doi:10.1007/s00024-014-1005-6

Sato T, Takahashi M (1996) Anomalous groundwater discharge after the 1995 Kobe earthquake in Awaji island - part II: change in discharge rate. Chishitsu News 506:24-28

Sato T, Sakai R, Furuya K, Kodama T (2000) Coseismic spring flow changes associated with the 1995 Kobe earthquake. Geophys Res Lett 27:1219-1222. doi:10.1029/1999GL011187

Silverii F, Cheloni D, D’Agostino N, Selvaggi G, Boschi E (2014) Post-seismic slip of the 2011 Tohoku-Oki earthquake from GPS observations: implications for depth-dependent properties of subduction megathrusts. Geophys J Int 198:580-596. doi:10.1093/gji/ggu149

Sun T, Wang K, linuma T, Hino R, He J, Fujimoto H, Kido M, Osada Y, Miura S, Ohta Y, Hu Y (2014) Prevalence of viscoelastic relaxation after the 2011 Tohoku-oki earthquake. Nature 514:84-87. doi:10.1038/nature13778

Tada A (1982) Structure of the basement and gravity anomaly in the Kanto Plain (1) — depth distribution of the basement. ZISIN (J Seismol Soc Jpn. 2nd ser.) 25:607-617

Takada Y, Fukushima Y (2013) Volcanic subsidence triggered by the 2011 Tohoku earthquake in Japan. Nature 6:637-641. doi:10.1038/ngeo 1857

Takahashi H (2011) Static strain and stress changes in eastern Japan due to the 2011 off the Pacific coast of Tohoku earthquakes, as derived from GPS data. Earth Planets Space 63:741-744. doi:10.5047/eps.2011.06.049

Tokunaga $T$ (1999) Estimating permeability change and specific yield from earthquake-induced hydrological changes: an example from Kobe earthquake. J Jpn Soc Eng Geol 40:99-106

Uetani T, Matsuoka T, Honda H (2016) Investigation of the conditions required for improved oil recovery by an earthquake. SPE Production \& Operations, SPE-168137-PA 9. doi:10.2118/168137-PA

Wang CY, Dreger DS, Wang CH, Wang D, Mayeri D, Berryman JG (2003) Field relations among coseismic ground motion, water level change, and liquefaction for the 1999 Chi-Chi (Mw = 7.5) earthquake, Taiwan. Geophys Res Lett 30(17):1890. doi:10.1029/2003GL017601

Wang K, HuY, He J (2012) Deformation cycles of subduction earthquakes in a viscoelastic Earth. Nature 484:327-332. doi:10.1038/nature11032

Yamagiwa S, Miyazaki S, Hirahara K, Fukahata Y (2015) Afterslip and viscoelastic relaxation following the 2011 Tohoku-oki earthquake (Mw9.0) inferred from inland GPS and seafloor GPS/Acoustic data. Geophys Res Lett 42(1):66-73. doi:10.1002/2014GL061735

Yamasaki T, Houseman GA (2012) The crustal viscosity gradient measured from post-seismic displacement: a case study of the 1997 Manyi (Tibet) earthquake. Earth Planet Sci Lett 351-352:105-1 14. doi:10.1016/j.epsl.2012.07.030

Yu B, Liu G, Zhang R, Jia H, Li T, Wang X, Dai K, Ma D (2013) Monitoring subsidence rates along road network by persistent scatterer SAR interferometry with high-resolution TerraSAR-X imagery. J Mod Transp 21(4):236-246. doi:10.1007/s40534-013-0030-y 